\title{
Diabetic nephropathy: is it always there? Assumptions, weaknesses and pitfalls in the diagnosis
}

\author{
Kyriakos loannou
}

Department of Nephrology, American Medical Center, Nicosia, Cyprus; Department of Nephrology, Apollonion Private Hospital, Nicosia, Cyprus; European University School of Medicine, Nicosia, Cyprus

\begin{abstract}
Diabetic nephropathy is defined as a microvascular complication of the kidneys induced by diabetes mellitus and is characterized by albuminuria and progressive loss of kidney function. However, neither albuminuria nor glomerular filtration rate decline are diabetic nephropathyspecific markers, thus the diagnosis of diabetic nephropathy greatly depends on assumptions. Several factors should be taken into account when urinary albumin levels are assessed before establishing the diagnosis of diabetic nephropathy, while newer more specific markers for diabetic nephropathy are urgently needed.
\end{abstract}

Key words: Diabetic nephropathy, Diabetic retinopathy, Microalbuminuria, Non-proteinuric diabetic kidney disease, Renal handling of albumin, SGLT1/SGLT2, Urine proteomics

\section{INTRODUCTION}

Diabetic nephropathy (DN) is defined as the microvascular complication of the kidneys induced by diabetes mellitus and is characterized by albuminuria and progressive loss of kidney function. It is considered as one of the microvascular complications of diabetes along with retinopathy and neuropathy. ${ }^{1,2}$ $\mathrm{DN}$ is vitrually the leading cause of end-stage kidney disease (ESKD). ${ }^{3-5}$ The prevalence of DN varies enormously between continents, countries and even between regions of the same country. ${ }^{5-9}$

However, the diagnosis of DN is an exclusion diagnosis depending on the presence of at least micro-

Address for correspondence:

Kyriakos Ioannou, 11 Halkis Str., Ap. 301, Nicosia 2107,

Cyprus; Tel.: +357 97770699, Fax: +357 22206958,

E-mail: kyr_ioannou@hotmail.com

Received: 03-05-2017, Accepted: 24-09-2017 albuminuria in a patient with a history of diabetes of at least 5 years. ${ }^{10} \mathrm{~A}$ kidney biopsy, which is the gold standard for definitive diagnosis, treatment guidance and prognosis for other types of nephropathies, is not indicated in diabetic patients, since the risk of such an intervention is not justified. This is mainly because there are no other treatment options available at present for $\mathrm{DN}$ beyond the current application of optimal control of diabetes, hypertension and dyslipidemia and lifestyle modification. ${ }^{10,11}$

Therefore, it could be postulated that the diagnosis of DN is highly subjective, depending on the doctor's judgment and experience when at least the above two criteria are fulfilled.

\section{NATURAL COURSE OF DN}

The natural course of DN was first described by Mogensen et al. ${ }^{12}$ Their description was in fact based 
on patients with type $1 \mathrm{DM}$, where the oncet is more or less obvious, and not on patients with type $2 \mathrm{DM}$, where the oncet is less pronounced and diagnosis may be delayed for 3-5 years.

According to Mogensen et al there are 5 stages in the course of DN (Figure1):

Stage 1, the stage at diagnosis, is characterized by hyperfiltration-increased estimated glomerular filtration rate (eGFR) and hypertrophy (increased kidney size). Increase in urinary albumin excretion can be present, aggravated during physical exercise, but these changes are at least partly reversible by insulin treatment.

Stage 2, the silent stage, develops over many years, without signs of clinical disease but still with characteristic morphologic lesions on biopsy specimens (glomerular basement membrane thickening, mesangial expansion). Estimated GFR may still be increased and albuminuria is transient. If diabetes is well controlled, albumin excretion is normal; however, physical exercise leads to an increase in albuminuria. By contrast, poor diabetes control leads to increased albumin excretion both during exercise and at rest.
A number of patients continue in stage 2 throughout their lives.

Stage 3, the incipient diabetic nephropathy stage, is characterized by abnormally elevated urinary albumin excretion, within the microalbuminuria range $30-300 \mathrm{mg} / 24 \mathrm{~h}$. Estimated GFR is still high or at least normal. Blood pressure is rising and albumin excretion is higher in patients with increased blood pressure.

Stage 4, the classic overt diabetic nephropathy stage, is characterized by persistent proteinuria $(>0.5$ $\mathrm{g} / 24 \mathrm{~h}$ ) and persistent high blood pressure and, if left untreated, eGFR declines at a mean rate of 1 $\mathrm{ml} / \mathrm{min} / 1.73 \mathrm{~m}^{2} / \mathrm{month}$. Long-term antihypertensive treatment reduces this eGFR decline rate by about $60 \%$ and delays uremia.

Stage 5 is end-stage renal failure with uremia due to diabetic nephropathy.

\section{RETINOPATHY AND DN}

Diabetic nephropathy (DN) and diabetic retinopathy (DR) are considered as interrelated diabetic vascular complications since kidneys and retina share similar

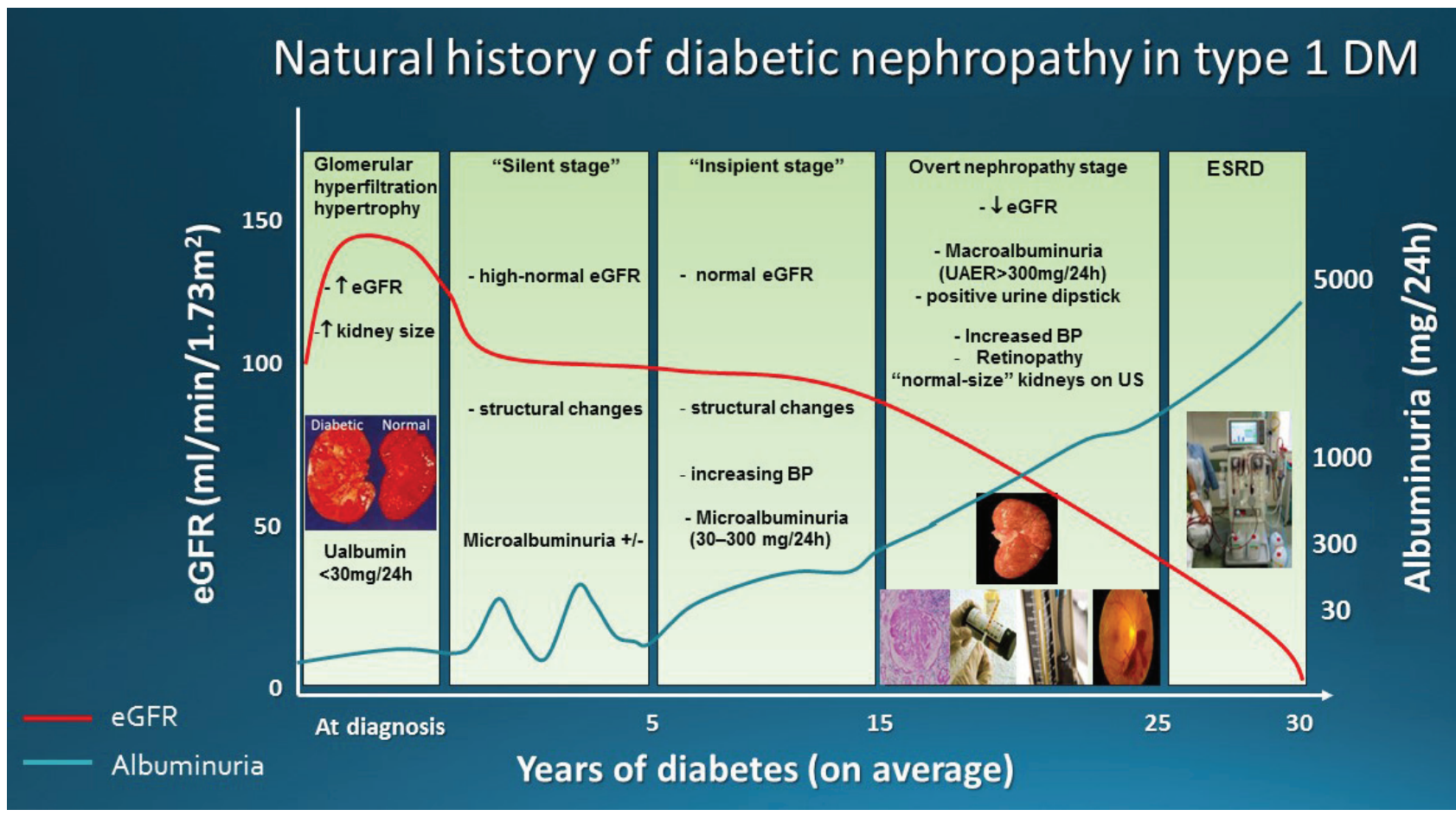

Figure 1. Natural history of diabetic nephropathy in type $1 \mathrm{DM}$, as described by Mogensen et al. 
size arteries. ${ }^{1,2}$ In clinical practice, the diagnosis of DR is used as the "non-interventional kidney biopsy" to diagnose $\mathrm{DN}$. Therefore, in a diabetic patient with a history of DM for at least 5 years and albuminuria, with or without decrease in eGFR, the co-existence of DR strengthens the clinical suspicion that the patient also has DN. However, the absence of DR cannot exclude DN, since DR is present in approximately $60 \%$ of DN cases. Prakash et al reported an absence of diabetic retinopathy in $43 \%$ of the cases with biopsyproven $\mathrm{DN}$, while non-diabetic kidney disease was reported in $40 \%$ of the cases in the presence of DR. ${ }^{13}$

Diabetic retinopathy incidence varies between studies and this probably relates to the duration of the cohorts. For example, in the UK type $2 \mathrm{DM}$ population studies, DR incidence was estimated to be $66 \%$ at 10 years and in the US population studies at $72.3 \%$ at 14 years. ${ }^{14}$ Diabetic retinopathy seems to better correlate with DN in type $1 \mathrm{DM}$ and much less in type 2. The prevalence of DR in type $1 \mathrm{DM}$ in Europe and the USA ranges between $36.5-93.6 \%$, while in type 2 DM in Western populations 28.5-40.3\%. ${ }^{14}$

Pedro et al observed a prevalence of $36.47 \%$ DR in type $1 \mathrm{DM}$ patients and $26.11 \%$ in type $2 \mathrm{DM}$ patients. ${ }^{15}$ In the same study, microalbuminuria was identified as a risk factor for DR in type $1 \mathrm{DM}$ patients but not for type 2, whereas overt nephropathy was better correlated with DR. ${ }^{15}$ Manaviat et al ${ }^{16}$ showed that the prevalence of any stage of DR in the microalbuminuria stage is quite low $(43 \%)$, while it increases in the overt proteinuria stage (79\%), probably reflecting the more advanced diabetic vascular disease, while DR is even present in $28 \%$ of patients with normoalbuminuria.

Therefore, DR does not serve as a reliable indicator of DN in patients with type $2 \mathrm{DM}$.

\section{MICROALBUMINURIA AS A MARKER OF ENDOTHELIAL DYSFUNCTION AND DN}

Microalbuminuria (MA) can occur both in patients with DM without present or future DN as well as in patients without DM but with other types of progressive chronic kidney disease and therefore it does not serve as a specific marker for the presence of DN. ${ }^{17}$ Mogensen et al showed that MA predicts early mortality in type $2 \mathrm{DM}$ and identified MA a cardiovascular and renal risk factor in both diabetic and non-diabetic subjects. ${ }^{18}$ Parving reported an increase in urinary albumin excretion rate in poorly controlled hypertensive patients ${ }^{19}$ and Bigazzi et al showed that MA predicts cardiovascular events and renal insufficiency in hypertensive patients..$^{20}$ Endothelial dysfunction has been suggested as underlying the renal and/or cardiovascular organ damage observed in these diseases. ${ }^{21}$

The Steno hypothesis proposed that an increased permeability of the vascular endothelium constitutes a high risk for microangiopathy and a tendency to large vessel disease. ${ }^{22}$ This systemic transvascular leakiness for albumin is associated with clinical atherosclerotic cardiovascular disease. ${ }^{23}$ The initiating event of the atherogenesis is endothelium 'injury', e.g. by hemodynamic stress or due to dyslipidemia and, according to the 'response-to-injury' hypothesis, the increased transendothelial permeability to macromolecules is such a type of response. ${ }^{24}$

Therefore, while MA better predicts the development of DN in type $1 \mathrm{DM}$, MA in type $2 \mathrm{DM}$ serves both as a marker of DN and of generalized endothelial dysfunction. Some type 2 DM patients with MA will not progress to the stage of overt proteinuria and these are probably the patients with hypertensive glomerulosclerosis compared to the patients that will progress and probably have diabetic glomerulosclerosis. It is obvious that in a type $2 \mathrm{DM}$ patient with MA, with or without eGFR decline, but with also a long-standing history of hypertension and general atherosclerotic vascular findings, even if both of the criteria for DN are fulfilled, one could not suggest that this is DN. Longer follow-up of both eGFR and proteinuria may be needed before the diagnosis of $\mathrm{DN}$ is set.

\section{REGRESSION OF MICROALBUMINURIA}

Microalbuminuria may not always be a marker of an irreversible renal injury, but most likely of acute renal stress and, due to this, not rarely regression of MA is observed. In some small studies MA progression rate to overt proteinuria has been reported to be high, i.e. $85 \%{ }^{18}$ and $87 \%{ }^{25}$ risk within 6 and 14 years, respectively, although this rate may be over- 
estimated. Perkins et $\mathrm{al}^{26}$ found this rate to be at $19 \%$ in a 6 -year follow-up, with approximately $60 \%$ of the patients showing regression to normal albumin excretion levels. This suggests a transient increase in albuminuria, especially in patients without optimal control of DM (HbA1c $>8 \%)$ and/or of hypertension. In such patients, MA decreases or even normalizes with improvement of DM and hypertension control, but again this is not evident in all patients. Patients who do not seem to improve MA despite DM control could be individuals with more atherosclerotic disease, i.e. smokers, chronic hypertensives and patients with long-standing hyperlipidemia, where MA possibly reflects a generalized vascular endothelial disease.

Therefore, assessing MA as a marker of renal disease in type 2 diabetics should only be made after establishing good DM, blood pressure and lipids control for a reasonable time period so that the transient character of MA is excluded. According to the National Kidney Foundation recommendations for Diabetes and Chronic Kidney Disease, ${ }^{27}$ patients with DM should be screened annually for DN. Initial screening should start 5 years after the diagnosis of type $1 \mathrm{DM}$ or from a diagnosis of type $2 \mathrm{DM}$ and should include measurements of urinary albumin to creatinine ratio (ACR) in a spot urine sample and serum creatinine and estimation of eGFR. Microalbumin must be measured in a first void urine sample and three samples are needed in a period of 3-6 months to establish the presence of MA.

\section{MICROALBUMINURIA: IS WHAT IS MEASURED IN THE URINE WHAT IS LEAKING FROM THE GLOMERULUS? FACTORS INFLUENCING ALBUMINURIA LEVELS.}

According to the current guidelines, for the establishment of a DN diagnosis detection of urinary albumin levels $>30 \mathrm{mg} / 24$ hours or ACR $>30 \mathrm{mg} / \mathrm{g}$ is crucial and mandatory. However, is the amount of albumin that we measure in the patient's urine what is really leaking from the damaged glomerulus (Figure 2)?

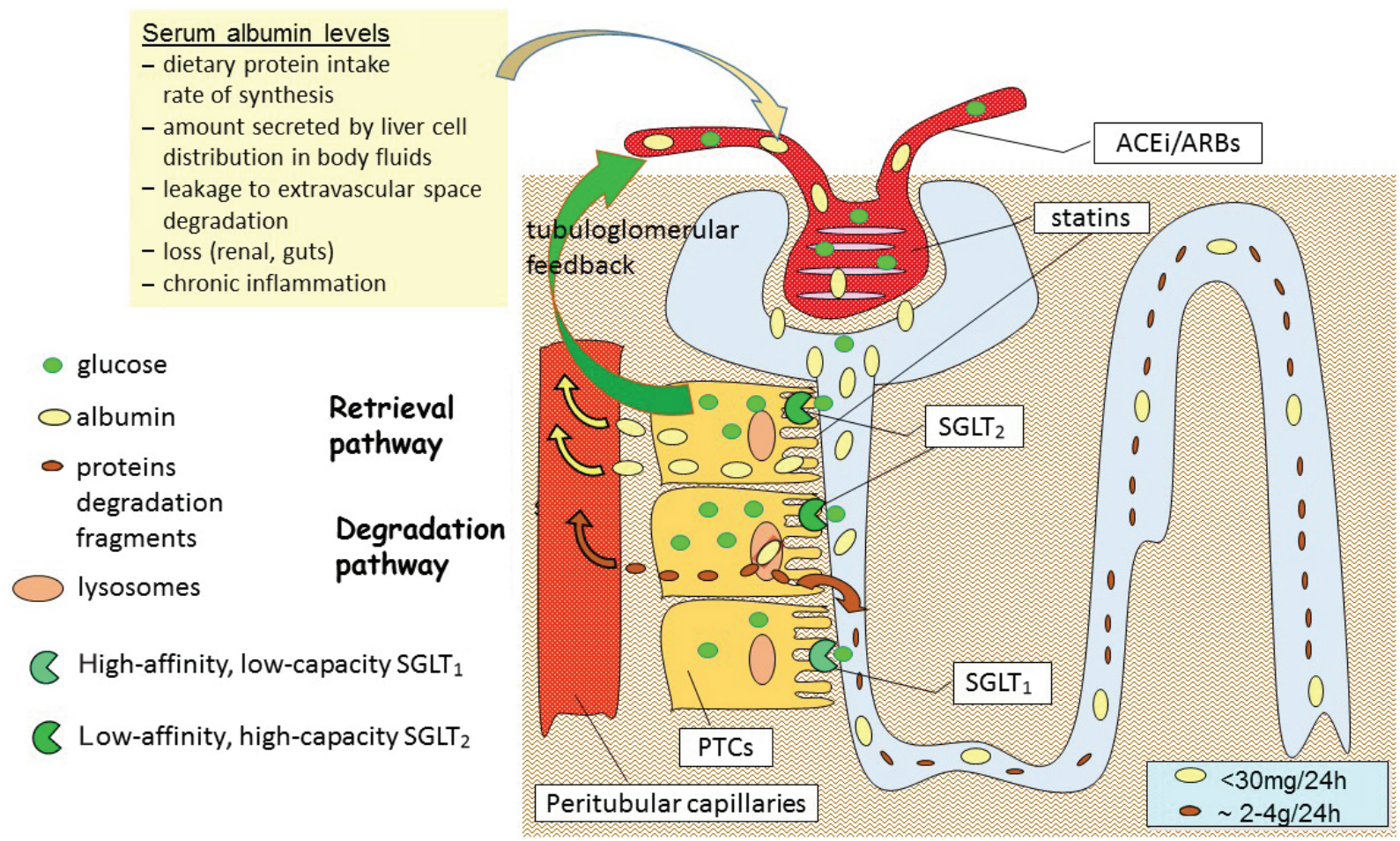

Figure 2. Factors influencing final urinary albumin levels. Albumin reabsorbed by the PTCs can return to the circulation either as intact albumin through a retrieval transcytotic pathway or as amino acids after being degraded in the lysosomes (degradation pathway). An amount of this degraded albumin is re-excreted in the urine as fractions of the initial molecule, not measured in urine samples when processed for MA measurement. 
First, the amount of albumin filtered through the glomerulus depends on the serum concentration of albumin. However, not all people have the same serum albumin levels. Serum albumin levels are dependent on dietary protein intake, the rate of synthesis and the amount secreted from the liver cells, the distribution in body fluids, the level of degradation and loss.

Habitual dietary protein intake varies significantly in humans depending upon age, gender and lean body mass, well known factors that influence GFR. ${ }^{28}$ Although there are reports suggesting that in healthy individuals dietary protein overload may not increase protein renal clearance, ${ }^{29,30}$ animal models showed that protein overload increases proteinuria. ${ }^{31,32}$ In humans also it was shown that consumption of excessive amounts of dietary protein promotes chronic renal disease through increased glomerular pressure and hyperfiltration ${ }^{33}$ and might be harmful in patients with CKD. ${ }^{34}$ Therefore, dietary differences in the amount of protein consumption may result in differences in GFR and albumin clearance and the amount of albumin measured in a urine sample.

On the other hand, hypoalbuminemia is a multifactorial process that results from a decrease in albumin synthesis as well as an increase in breakdown, leakage to the extravascular space and decreased protein intake..$^{35}$ Patients with obvious malnutrition, malabsorption syndrome (protein-losing enteropathy) or hepatic dysfunction and a chronic inflammatory state may have lower albumin serum levels due to lower intake, absorption or synthesis of albumin. Therefore, for the same degree of glomeruli damage, these patients are expected to have lower urine albumin levels due to the lower amount of plasma albumin filtered by the kidneys.

Second, for more than 30 years filtered albumin has been known to be reabsorbed by the proximal tubular cells (PTCs). ${ }^{36}$ Despite the low, i.e. less than $30 \mathrm{mg} /$ day, amount of albumin found in final urine, this represents only the intact albumin that can be measured by available laboratory methods. It is known that filtered albumin is reabsorbed mainly by the proximal tubule and to a lesser extent by downstream parts of the nephron. ${ }^{37}$ Albumin reabsorbed by the PTCs can return to the circulation either as intact albumin through a retrieval transcytotic pathway or as amino acids after being degraded in the lysosomes (degradation pathway). ${ }^{38,39}$ An amount of this degraded albumin is re-excreted in the urine as fractions of the initial molecule, not measured in urine samples when they are processed for MA measurement (Figure 2). The protein content of the final urine has been estimated to be as high as 2 to $4 \mathrm{~g} /$ day $^{40,41}$ and the amount of filtered albumin has been estimated to be 50 times higher than previously assumed, suggesting that on a daily basis the normal kidney filters nephrotic levels of albumin, most of it retrieved by the proximal tubules. ${ }^{42,43}$

Furthermore, beyond the glomerulus, the proximal tubule also seems to contribute to DN pathology. Normally, under euglycemic conditions approximately $97 \%$ of filtered glucose is reabsorbed via the low-affinity-high-capacity $\mathrm{Na}^{+}$-glucose cotransporter SGLT2, primarily in the early segments of the proximal tubule, and 3\% is reabsorbed via the highaffinity-low-capacity SGLT1 in the late segments of the proximal tubule. ${ }^{44}$ Hyperglycemia enhances the amounts of glucose filtered by the glomeruli and thus increases glucose delivery to both SGLT2 and SGLT1 enhancing glucose reabsorption in the proximal tubule. Glucose transporters GLUT2 and GLUT1 mediate glucose transport across the basolateral membrane, but GLUT2 may also translocate to the apical membrane in diabetes. ${ }^{45}$

Proximal tubular cells appear unable to decrease glucose transport rates adequately to prevent excessive changes in intracellular glucose when exposed to high glucose concentrations ${ }^{46}$ and this leads to the notable growth phenotype of early diabetic proximal tubule hyperplasia followed by hypertrophy. ${ }^{47}$ In the setting of normal tubuloglomerular feedback, this increased glucose tubular absorption leads to a strong tubular control of glomerular filtration in the early diabetic kidney, further enhancing glomerular hyperfiltration and proteinuria. ${ }^{45,47}$

Therapeutic agents, which have been developed to inhibit SGLT-2 or to effect dual inhibition of SGLT-2/ SGLT-1 and are currently used for diabetes control in type $2 \mathrm{DM}$ and type $1 \mathrm{DM}$, respectively, are also expected to intervene in these processes. ${ }^{48,49}$

SGLT2 inhibitors could potentially exert nephro- 
protection not only through improved glycemic control but also through glucose-independent effects. Such effects are the blood pressure-lowering effect, since these reduce sodium reabsorption in the proximal tubule, but also afferent arteriole vasoconstriction through the tubuloglomerular feedback which leads to attenuation of diabetes-associated hyperfiltration and tubular hypertrophy and reduction in albuminuria, independent of their effects on blood pressure or glucose control..$^{50,51}$

SGLT2 inhibition and the associated afferent vasoconstriction leads to an acute, dose-dependent reduction in eGFR by approximately $5 \mathrm{ml} / \mathrm{min} / 1.73 \mathrm{~m}^{2}$ and in albuminuria by approximately $30 \%$ to $40 \% .^{52}$ Thus, the decrease in glomerular hyperfiltration following good diabetes control in general could in part explain the decrease in MA in clinical practice, while SGLT 2 inhibitors contribute to this through additional glucose-independent effects.

It is obvious that the anatomical and functional integrity of the proximal tubule is crucial for the final amount of albumin found in the urine and thus for the diagnosis of DN. Diseases other than diabetes that affect the PTCs,$^{53}$ but also such drugs as cisplatin, ifosfamide, tenofovir, sodium valproate and aminoglycoside antibiotics, may influence PTCs function and interfere with MA levels. ${ }^{54}$

Angiotensin-converting enzyme inhibitors (ACEinh) and angiotensin II receptor antagonists (ARBs) are probably the most common classes of antihypertensive drugs prescribed in diabetic patients. Beyond their beneficial effects on cardiovascular risk factors and all-cause mortality, both categories have been shown in several studies also to have beneficial renal outcomes, including time to end-stage renal failure or doubling of creatinine, but also in preventing progression of micro- to macroalbuminuria or even remission of micro- to normoalbuminuria, ${ }^{55-58}$ thus intervening in the result of albumin measurement in urine.

3-hydroxy-3-methylglutaryl coenzyme A (HMG$\mathrm{CoA}$ ) reductase inhibitors, referred to as "statins", widely used in diabetics for lipids control and cardiovascular protection, ${ }^{59-61}$ have been shown also to increase albumin endocytosis by glomerular epithelial cells (podocytes), suggesting another pathway of retrieving albumin that leaks through the glomerular filtration barrier. ${ }^{62-64}$ Conversely, statins have been shown to reduce albumin endocytosis by PTCs and may enhance albuminuria. ${ }^{65,66}$

Taking all the above into account, it could be postulated that the amount of albumin detected in a spot urine sample, which is the criterion in order to characterize a patient as having $\mathrm{DN}$ or not, is the net result of several parameters that are both patient related (degree of glomerular damage, proximal tubular integrity, serum albumin levels), but also health professionals related (use of therapeutic agents that influence glomerular filtration of albumin such as ACE-inh/ARBs or statins, or tubular processing of the filtered albumin like SGLT2 inhibitors, as well as the degree of hypertension, glycemic and lipids control in general). Therefore, for the same amount of MA detected, the degree of the actual diabetic glomerular damage may not be the same, therefore the diagnosis of DN should be individualized and carefully set after assessment of all possible parameters that may influence this process.

\section{MICROALBUMINURIA: IS IT THE BEST WE CAN DO FOR EARLY DETECTION OF DN?}

It has already been more than two decades since the first announcements of MA being an early marker of DN and, until lately, it has been regarded as the gold standard for the diagnosis and a predictor of progression to end-stage kidney disease in both type $1^{67}$ and type 2 diabetes. ${ }^{68}$

However, as already analyzed above, though MA is an accessible and affordable screening marker for daily clinical practice, its predictive strength is not robust. On this account, scientists have put their efforts into identifying new markers that precede the microalbuminuria stage and are more predictive of the early stages, but also of progression of DN. In this effort, the development of new diagnostic methods and especially the omics and microRNAs technology has led to novel markers, mainly from the urine that could support this strategy.

A number of key biomarkers present in the urine that reflect the pathophysiologic processes taking place in the diabetic kidney along the nephron (glo- 
merulus/podocytes, tubules) and also reflect the different mechanisms (tubular damage, oxidative stress, inflammation and activation of the intrarenal reninangiotensin system) have been identified. ${ }^{69-71}$ For example, podocytes injury and/or decrease in their number per glomerulus is an early finding in $\mathrm{DN}$, even prior to proteinuria, and therefore podocyturia- and podocyte-specific markers in the urine, including nephrin or Wilm's tumor-1 protein, could serve as early biomarkers of $\mathrm{DN} .{ }^{72,73}$

Nephrinuria was present in $100 \%$ of type 2 diabetic patients with microalbuminuria and macroalbuminuria, but also in $54 \%$ of type 2 diabetic patients with normoalbuminuria. ${ }^{74}$ Positive urinary Wilms' Tumor- 1 (WT1) protein was detected in 50\% of diabetic patients without proteinuria, while in nondiabetic control subjects urinary WT1 was virtually absent. ${ }^{73}$

Vascular endothelial growth factor A (VEGF-A), a podocyte-derived biomarker, could also be a sensitive early marker of DN, but also a disease progression marker. VEGF urinary excretion was significantly higher in diabetics, even in the absence of albuminuria, compared to nondiabetic healthy controls, and urinary VEGF levels increased as DN advanced. ${ }^{75}$

Other podocytes markers could also be found early in the urine of diabetic patients, but their specificity might be an issue. For example, podocalyxin was found to increase in the urine of $53.8 \%$ of normoalbuminuric diabetic patients $;{ }^{76}$ however, podocalyxin is also expressed in other renal and non-renal cells. ${ }^{77}$

Urinary transferrin may also be a sensitive marker of glomerular damage in patients with diabetes, even in the absence of albuminuria; ${ }^{78}$ on the other hand, as with albumin it is not DN-specific, since other primary glomerular diseases also increase its excretion. ${ }^{79}$

Beyond podocytes (glomerular epithelium), glomerular endothelium has also been implicated in diabetic kidney disease pathophysiolgy and other microvascular complications in diabetes. Diabetic patients excrete in urine significantly more glycosaminoglycans (GAGs), part of the endothelial glycocalyx, than controls ${ }^{80}$ and such an increase has been reported in patients with all stages of albuminuria, while urinary GACs positively correlated with disease progression. ${ }^{81}$
Moreover, several other proteins have been reported to increase in the urine of diabetic patients. Extracellular structural matrix proteins (collagen type IV, fibronectin, metalloproteinases), transforming growth factor (TGF)beta the potent inducer of extracellular matrix proteins, markers of tubular damage like the apical membrane receptors megalin and cubilin, the transmembrane protein of the apical membrane of PTCs-kidney injury molecule 1 (KIM-1), but also neutrophil gelatinase-associated lipocalin (NGAL) that is produced in the distal nephron are examples of such proteins. Furthermore, proteins that are normally freely filtered by the glomerulus and reabsorbed by the PCTs, including $\alpha 1$-microglobulin and retinol-binding protein, are also reported to increase in urine. Most of these proteins increase even in the normoalbuminuric stage, ${ }^{69,70}$ with some of them being detected up to 5 years prior to the onset of macroalbuminuria. ${ }^{71}$

\section{NON-DIABETIC NEPHROPATHY IN DIABETIC PATIENTS}

When a diabetic patient develops clinical nephropathy with proteinuria, this could be due to progressive diabetic nephropathy, or another nondiabetic glomerulopathy, or both. It has been reported that another primary glomerulopathy may rarely $(2-3 \%)$ implicate insulin dependent diabetes, ${ }^{82}$ but from $10 \%{ }^{83}$ to as much as $25 \%{ }^{84}$ of non-insulin dependent diabetes cases. Among diabetic patients who clinically were suspected not to have diabetic nephropathy and underwent a renal biopsy, Soni et al ${ }^{85}$ reported that the most common non-diabetic renal diseases were acute interstitial nephritis $18.1 \%$, post infectious glomerulonephritis $17.24 \%$, membranous nephropathy $11.20 \%$ and focal segmental glomerulosclerosis $7.75 \%$.

Furthermore, even if diabetic changes such as diffuse and nodular glomerulosclerosis are found in the kidney biopsy, it is important to determine whether these are secondary changes due to diabetic nephropathy or are due to another renal disease, e.g. segmental glomerulosclerosis or idiopathic nodular glomerulosclerosis, in addition to diabetic nephropathy. ${ }^{86}$ Other nephropathies that share similar nodular histological features with diabetic nephropathy such as membranoproliferative glomerulonephritis, mono- 
clonal immunoglobulin deposition disease, amyloidosis, fibrillar glomerulopathy and idiopathic nodular glomerulosclerosis could be distinguished by detailed histopathological evaluation. ${ }^{86,87}$

On the other hand, many diabetic patients with chronic kidney disease may not have significant proteinuria or albuminuria even in the late CKD stages and, therefore, classic diabetic nephropathy does not appear to be the underlying renal lesion. ${ }^{88}$ These subjects may represent almost $50 \%$ of diabetic patients with renal insufficiency and are more often older patients with a history of cardiovascular disease and usually treated with renin-angiotensin system blockers. ${ }^{89,90}$ Disease progression in this subgroup is slower, although histological analyses may show surprisingly advanced glomerular lesions. ${ }^{89}$ The latter histological findings are more frequently seen in type $1 \mathrm{DM}$, whereas in type $2 \mathrm{DM}$ a substantial proportion of patients have more advanced tubulo-interstitial and vascular than glomerular lesions. ${ }^{91,92}$ On this basis, Dalla Vestra et $\mathrm{a}^{93}$ have proposed a different classification system for renal lesions in diabetic kidney disease, comprising three major groups: I) normal or near-normal renal structure (41\%), II) typical diabetic nephropathology (26\%) and III) atypical patterns of renal injury $(33 \%)$ where there are only mild diabetic glomerular lesions and disproportionately more profound tubulo-interstitial lesions, advanced glomerular arteriolar hyalinosis and global glomerular sclerosis, in all possible combinations.

\section{CONCLUSION}

Microalbuminuria is currently used as the earliest marker for diabetic nephropathy. However, several limitations exist, since urinary albumin levels depend on several patient-related factors or health care professionals' interventions. Additionally, renal impairment could also occur even at the normoalbuminuric stage. Urinary biomarkers that are significantly elevated even in normoalbuminuric diabetic patients prior to the development of microalbuminuria could be promising biomarkers of DN at a very early stage. Nevertheless, larger multicenter prospective studies are needed to confirm their clinical utility and costeffectiveness as a screening tool for daily practice. Until then, albuminuria must continue to be used as a marker of kidney damage in DM, but it must also be carefully assessed and monitored for a reasonable time period before setting the diagnosis of DN. If unexpectedly renal function deterioration occurs or overt proteinuria develops, nephrology consultation is advisable to exclude other primary renal pathology.

\section{CONFLICT OF INTEREST}

None.

\section{REFERENCES}

1. Orasanu G, Plutzky J, 2009 The pathologic continuum of diabetic vascular disease. J Am Coll Cardiol 53: 5 Suppl: 35-42.

2. The ADVANCE Collaborative Group, 2008. Intensive Blood Glucose Control and Vascular Outcomes in Patients with Type 2 Diabetes. N Engl J Med 358: 2560-2572.

3. Narres M, Claessen H, Droste S, et al, 2016 The Incidence of End-Stage Renal Disease in the Diabetic (Compared to the Non-Diabetic) Population: A Systematic Review. PLoS One 11: e0147329.

4. The European Renal Association - European Dialysis and Transplant Association Registry Annual Report 2014, 2017: a summary. Clin Kidney J 10: 154-169.

5. USRDS 2015 Annual Data Report. Chapter 1: Incidence, Prevalence, Patient Characteristics, and Treatment Modalities. https://www.usrds.org/2015/view.

6. Gheith O, Farouk N, Nampoory N, Halim MA, Al-Otaibi T, 2016 Diabetic kidney disease: worldwide difference of prevalence and risk factors. J Nephropharmacol 5: 49-56.

7. Martínez-Castelao A, Navarro-González JF, Górriz JL, de Alvaro F, 2015 The Concept and the Epidemiology of Diabetic Nephropathy Have Changed in Recent Years. J Clin Med 4: 1207-1216.

8. de Boer IH, Rue TC, Hall YN, et al, 2011 Temporal trends in the prevalence of diabetic kidney disease in the United States. JAMA 305: 2532-2539.

9. Parving H, Lewis J, Ravid M, et al, 2006 Prevalence and risk factors for microalbuminuria in a referred cohort of type II diabetic patients: a global perspective. Kidney Int 69: 2057-2063.

10. National Kidney Foundation, KDOQI Clinical Practice Guideline for Diabetes and CKD: 2012 Update, 2012. Am J Kidney Dis 60: 850-886.

11. American Diabetes Association, 2014 Standards of medical care in diabetes-2014. Diabetes Care 37: Suppl 1: 14-80.

12. Mogensen CE, Christensen CK, Vittinghus E, 1983 The stages in diabetic renal disease. With emphasis on the stage of incipient diabetic nephropathy. Diabetes 32: 64-78. 
13. Prakash J, Gupta T, Prakash S, et al, 2015. Non-diabetic renal disease in type 2 diabetes mellitus: Study of renal - retinal relationship. Indian J Nephrol 25: 222-228.

14. Lee R, Wong TY, Sabanayagam C, 2015. Epidemiology of diabetic retinopathy, diabetic macular edema and related vision loss. Eye Vis (Lond) 2: 17.

15. Pedro RA, Ramon SA, Marc BB, Juan FB, Isabel MM, 2010 Prevalence and relationship between diabetic retinopathy and nephropathy, and its risk factors in the North-East of Spain, a population-based study. Ophthalmic Epidemiol 17: 251-265.

16. Manaviat MR, Afkhami M, Shoja MR, 2004 Retinopathy and microalbuminuria in type II diabetic patients. BMC Ophthalmology 4: 9.

17. Glassock RJ, 2010 Is the presence of microalbuminuria a relevant marker of kidney disease? Curr Hypertens Rep 12: 364-368.

18. Mogensen CE, Christensen CK, 1984 Predicting diabetic nephropathy in insulin-dependent patients. N Engl J Med 311: 89-93.

19. Parving HH, 1996 Microalbuminuria in essential hypertension and diabetes. J Hypertens 14: S89-S94.

20. Bigazzi R, Bianchi S, Baldari D, Campese VM, 1998 Microalbuminuria predicts cardiovascular events and renal insufficiency in patients with essential hypertension. J Hypertens 16: 1325-1333.

21. Stevenson JM, 1995 Is parental hypertension a risk factor for the development of nephropathy in type 1 diabetes? Nephrol Dial Transplant 10: 448-450.

22. Deckert T, Feldt-rasmussen B, Borch-Johnsen K, Jensen T, Kofoed-Enevoldsen A, 1989 Albumunuria reflects underspread vascular damage: the steno hypothesis. Diabetelogia 32: 219-226.

23. Jensen JS, Borch-Johnsen K, Jensen G, Feldt-Rasmussen B, 1995 Microalbuminuria reflects a generalized transvascular albumin leakiness in clinically healthy subjects. Clin Sci (Lond) 88: 629-633.

24. Ross R, 1986 The pathogenesis of atherosclerosis - an update. N Engl J Med 314: 488-500.

25. Viberti GC, Hill RD, Jarrett RJ, et al, 1982 Microalbuminuria as a predictor of clinical nephropathy in insulindependent diabetes mellitus. Lancet 1: 1430-1432.

26. Perkins BA, Ficociello LH, Silva KH, et al, 2003 Regression of Microalbuminuria in Type 1 Diabetes. $\mathrm{N}$ Engl J Med 348: 2285-2293.

27. National Kidney Foundation, 2007 KDOQI Clinical Practice Guidelines and Clinical Practice Recommendations for Diabetes and Chronic Kidney Disease. Am J Kidney Dis 49: Suppl 2: 1-180.

28. King AJ, Levey AS, 1993 Dietary protein and renal function. J Am Soc Nephrol 3: 1723-1737.

29. Poortmans JR, Dellalieux O, 2000 Do regular high protein diets have potential health risks on kidney function in athletes? Int J Sport Nutr Exerc Metab 10: 28-38.

30. Lemon PW, 1996 Is increased dietary protein necessary or beneficial for individuals with a physically active lifestyle? Nutr Rev 544: S69-175.

31. Weening JJ, Van Guldener C, Daha MR, et al, 1987 The pathophysiology of protein-overload proteinuria. Am J Pathol 129: 64-73.

32. Bliss DJ, Brewer DB, 1985 Increased albumin and normal dextran clearances in protein-overload proteinuria in the rat. Clin Sci (Lond) 69: 321-326.

33. Brenner BM, Meyer TW, Hostetter TH, 1982 Dietary protein intake and the progressive nature of kidney disease: the role of hemodynamically mediated glomerular injury in the pathogenesis of progressive glomerular sclerosis in aging, renal ablation, and intrinsic renal disease. N Engl J Med 307: 652-659.

34. Friedman AN, 2004 High-protein diets: potential effects on the kidney in renal health and disease. Am J Kidney Dis 44: 950-962.

35. Ballmer P.E, 2001 Causes and mechanisms of hypoalbuminemia. Clinical Nutrition 20: 271-273.

36. Park CH, Maack T, 1984 Albumin absorption and catabolism by isolated perfused proximal convoluted tubules of the rabbit. J Clin Invest 73: 767-777.

37. Tojo A, Kinugasa S, 2012 Mechanisms of glomerular albumin filtration and tubular reabsorption. Int J Nephrol 2012: 481520.

38. Dickson LE, Wagner MC, Sandoval RM, Molitoris BA, 2014 The proximal tubule and albuminuria: really! J Am Soc Nephrol 25: 443-453.

39. Birn H, Christensen EI, 2006 Renal albumin absorption in physiology and pathology. Kidney Int 69: 440-449

40. Tojo A, Endou H, 1992 Intrarenal handling of proteins in rats using fractional micropuncture technique. Am J Physiol 263: F601-606.

41. Osicka TM, Houlihan CA, Chan JG, et al, 2000 Albuminuria in patients with type 1 diabetes is directly linked to changes in the lysosome-mediated degradation of albumin during renal passage. Diabetes 49: 1579-1584.

42. Russo LM, Sandoval RM, McKee M, et al, 2007 The normal kidney filters nephrotic levels of albumin retrieved by proximal tubule cells: Retrieval is disrupted in nephrotic states. Kidney Int 71: 504-513.

43. M.Gekle, 2007 Renal albumin handling: A look at the dark side of the filter. Kidney Int 71: 479-481.

44. Vallon V, Platt KA, Cunard R, et al, 2011 SGLT2 mediates glucose reabsorption in the early proximal tubule. J Am Soc Nephrol 22: 104-112.

45. Vallon V, 2011 The proximal tubule in the pathophysiology of the diabetic kidney. Am J Physiol Regul Integr Comp Physiol 300: R1009-R1022.

46. Morrisey K, Steadman R, Williams JD, Phillips AO, 1999 Renal proximal tubular cell fibronectin accumulation in response to glucose is polyol pathway dependent. Kidney Int 55: 160-167.

47. Thomson SC, Deng A, Bao D, et al, 2001 Ornithine decarboxylase, kidney size, and the tubular hypothesis of glomerular hyperfiltration in experimental diabetes. J Clin Invest 107: 217-224. 
48. Chao EC, 2014 SGLT-2 Inhibitors: A New Mechanism for Glycemic Control. Clinical Diabetes 32: 4-11.

49. Sands AT, Zambrowicz BP, Rosenstock J, et al, 2015 Sotagliflozin, a Dual SGLT1 and SGLT2 Inhibitor, as Adjunct Therapy to Insulin in Type 1 Diabetes. Diabetes Care 38: 1181-1188.

50. Fioretto P, Zambon A, Rossato M, Busetto L, Vettor R, 2016 SGLT2 Inhibitors and the Diabetic Kidney. Diabetes Care 39: Suppl 2: 165-171.

51. Thomas MC, 2014 Renal effects of dapagliflozin in patients with type 2 diabetes. Ther Adv Endocrinol Metab 5: 53-61.

52. Heerspink HJL, Perkins BA, Fitchett DH, Husain M, Cherney DZI, 2016 Sodium Glucose Cotransporter 2 Inhibitors in the Treatment of Diabetes Mellitus. Cardiovascular and Kidney Effects, Potential Mechanisms, and Clinical Applications. Circulation 134: 752-772.

53. Haque SK, Ariceta G, Batlle D, 2012 Proximal renal tubular acidosis: a not so rare disorder of multiple etiologies. Nephrol Dial Transplant 27: 4273-4287.

54. Hall AM, Bass P, Unwin RJ, 2014 Drug-induced renal Fanconi syndrome. QJM 107: 261-269.

55. de Jong PE, Heeg JE, Apperloo AJ, de Zeeuw D, 1992 The antiproteinuric effects of blood pressure-lowering agents: differences between nondiabetics and diabetics. J Cardiovasc Pharmacol 19: Suppl 6: 28-32.

56. Cooper ME, 1996 Renal protection and angiotensin converting enzyme inhibition in microalbuminuric type I and type II diabetic patients. J Hypertens 14: Suppl: 11-14.

57. Jerums G, Allen TJ, Campbell DJ, et al, 2004 Melbourne Diabetic Nephropathy Study Group. Long-term renoprotection by perindopril or nifedipine in non-hypertensive patients with Type 2 diabetes and microalbuminuria. Diabet Med 21: 1192-1199.

58. Strippoli GF, Bonifati C, Craig M, Navaneethan SD, Craig JC, 2006 Angiotensin converting enzyme inhibitors and angiotensin II receptor antagonists for preventing the progression of diabetic kidney disease. Cochrane Database Syst Rev: CD006257.

59. Colhoun HM, Betteridge DJ, Durrington PN, et al, 2004 Primary prevention of cardiovascular disease with atorvastatin in type 2 diabetes in the Collaborative Atorvastatin Diabetes Study (CARDS): multicentre randomised placebo-controlled trial. Lancet 364: 685-696.

60. 2002 MRC/BHF Heart Protection Study of cholesterol lowering with simvastatin in 20,536 high-risk individuals: a randomised placebo-controlled trial. Lancet 360: 7-22.

61. Taylor F, Huffman MD, Macedo AF, et al, 2013 Statins for the primary prevention of cardiovascular disease. Cochrane Database Syst Rev: CD004816.

62. Eyre J, Ioannou K, Grubb BD, et al, 2007 Statin-sensitive endocytosis of albumin by glomerular podocytes. Am J Physiol Renal Physiol 292: F674-681.

63. Castrop H, Schieß1 IM, 2017 Novel routes of albumin passage across the glomerular filtration barrier. Acta Physiol (Oxf) 219: 544-553.
64. Carson JM, Okamura K, Wakashin H, et al, 2014 Podocytes degrade endocytosed albumin primarily in lysosomes. PLoS One 9: e99771.

65. Sidaway JE, Davidson RG, McTaggart F, et al, 2004 Inhibitors of 3-hydroxy-3-methylglutaryl-CoA reductase reduce receptor-mediated endocytosis in opossum kidney cells. J Am Soc Nephrol 15: 2258-2265.

66. Verhulst A, D’Haese PC, De Broe ME, 2004. Inhibitors of HMG-CoA reductase reduce receptor-mediated endocytosis in human kidney proximal tubular cells. J Am Soc Nephrol 15: 2249-2257.

67. Perkins BA, Ficociello LH, Roshan B, Warram JH, Krolewski AS, 2010. In patients with type 1 diabetes and new-onset microalbuminuria the development of advanced chronic kidney disease may not require progression to proteinuria. Kidney Int 77: 57-64.

68. Adler AI, Stevens RJ, Manley SE, et al, 2003 UKPDS GROUP. Development and progression of nephropathy in type 2 diabetes: the United Kingdom Prospective Diabetes Study (UKPDS 64). Kidney Int 63: 225-232.

69. Lee SY, Choi ME, 2015 Urinary biomarkers for early diabetic nephropathy: Beyond albuminuria. Pediatr Nephrol 30: 1063-1075.

70. Fiseha T, 2015 Urinary biomarkers for early diabetic nephropathy in type 2 diabetic patients. Biomark. Res 3: 16.

71. Zürbig P, Jerums G, Hovind P, et al, 2012 Urinary proteomics for early diagnosis in diabetic nephropathy. Diabetes 61: 3304-3313.

72. Pätäri A, Forsblom C, Havana M, et al, 2003 Nephrinuria in diabetic nephropathy of type 1 diabetes. Diabetes 52: 2969-2974.

73. Kalani A, Mohan A, Godbole MM, et al, 2013 Wilm's tumor-1 protein levels in urinary exosomes from diabetic patients with or without proteinuria. PLoS One 8: e60177.

74. Jim B, Ghanta M, Qipo A, et al, 2012 Dysregulated nephrin in diabetic nephropathy of type 2 diabetes: a cross sectional study. PLoS One 7: e36041.

75. Kim NH, Oh JH, Seo JA, et al, 2005 Vascular endothelial growth factor (VEGF) and soluble VEGF receptor FLT-1 in diabetic nephropathy. Kidney Int 67: 167-177.

76. Hara M, Yamagata K, Tomino Y, et al, 2012 Urinary podocalyxin is an early marker for podocyte injury in patients with diabetes: establishment of a highly sensitive ELISA to detect urinary podocalyxin. Diabetologia 55: 2913-2919.

77. Nielsen JS, McNagny KM, 2009 The role of podocalyxin in health and disease. J Am Soc Neph 20: 1669-1676.

78. Narita T, Sasaki H, Hosoba M, et al, 2004 Parallel increase in urinary excretion rates of immunoglobulin $\mathrm{G}$, ceruloplasmin, transferrin, and orosomucoid in normoalbuminuric type 2 diabetic patients. Diabetes Care 27: 1176-1181.

79. Mackinnon B, Shakerdi L, Deighan CJ, et al, 2003 Urinary transferrin, high molecular weight proteinuria and the progression of renal disease. Clin Nephrol 59: 
252-258.

80. Nieuwdorp M, Mooij HL, Kroon J, et al, 2006 Endothelial glycocalyx damage coincides with microalbuminuria in type 1 diabetes. Diabetes 55: 1127-1132.

81. Popławska-Kita A, Mierzejewska-Iwanowska B, Szelachowska M, et al, 2008 Glycosaminoglycans urinary excretion as a marker of the early stages of diabetic nephropathy and the disease progression. Diabetes Metab Res Rev 24: 310-317.

82. Olsen S, 1999 Identification of non-diabetic glomerular disease in renal biopsies from diabetics--a dilemma. Nephrol Dial Transplant 14: 1846-1849.

83. Olsen S, Mogensen CE, 1996 How often is NIDDM complicated with non-diabetic renal disease? An analysis of renal biopsies and the literature. Diabetologia 39: 1638-1645.

84. Parving $\mathrm{HH}^{1}$, Gall MA, Skøtt P, Jørgensen HE, 1992 Prevalence and causes of albuminuria in non-insulindependent diabetic patients. Kidney Int 41: 758-762.

85. Soni SS, Gowrishankar S, Kishan AG, Raman A, 2006. Non diabetic renal disease in type 2 diabetes mellitus. Nephrology (Carlton) 11: 533-537.

86. Alsaad KO, Herzenberg AM, 2007 Distinguishing dia- betic nephropathy from other causes of glomerulosclerosis: an update. J Clin Pathol 60: 18-26.

87. Raparia K, Usman I, Kanwar YS, 2013 Renal morphologic lesions reminiscent of diabetic nephropathy. Arch Pathol Lab Med 137: 351-359.

88. Robles NR, Villa J, Gallego RH, 2015 Non-Proteinuric Diabetic Nephropathy. J Clin Med 4: 1761-1773.

89. Halimi JM, 2012 The emerging concept of chronic kidney disease without clinical proteinuria in diabetic patients. Diabetes Metab 38: 291-297.

90. Penno G, Solini A, Bonora E, et al, 2011 Clinical significance of nonalbuminuric renal impairment in Type 2 diabetes. J. Hypertens 29: 1802-1809.

91. Fioretto P, Mauer M, Brocco E, et al, 1996 Patterns of renal injury in Type 2 (non-insulin-dependent) diabetic patients with microalbuminuria. Diabetologia 39: 1569-1576.

92. Brocco E, Fioretto P, Mauer M, et al, 1997 Renal structure and function in non-insulin-dependent diabetic patients with microalbuminuria. Kidney Int 52: S40-S44.

93. Dalla Vestra M, Saller A, Bortoloso E, Mauer M, Fioretto $\mathrm{P}, 2000$. Structural involvement in Type 1 and Type 2 diabetic nephropathy. Diabetes Metab 26: Suppl 4: 8-1. 